\title{
Relevance Of Medical Records Management Of Health Care Services Delivery. Case Study Of Jinja Referral Hospital Jinja Municipality.
}

\author{
Boniface Adrinko ${ }^{a}, 1$, Fredrick Wandara ${ }^{a}$ \\ ${ }^{a}$ Medical Records Department, St. Francis School of Health Sciences, \\ Nakifuma County, Nagojje Sub-county - Namataba - Mukono District, Uganda.
}

Abstract

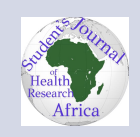

Background

The study sought to investigate the relevance of medical records management on healthcare service delivery in Jinja referral hospital Jinja municipality. The objectives of the study were to describe the present records management practices in Jinja Referral Hospital; find out the existing infrastructure for the management of patient medical records at the Jinja Referral Hospital; determine the compliance of patient medical records management in Jinja Referral Hospital with the relevant national legislative and regulatory framework; find out the security of patient medical records at the Jinja Referral Hospital.

\section{Methodology}

Quantitative and qualitative approaches were employed, the sample was drawn from the service providers and from the healthcare service users. Questionnaires, interviews, and observation were used to collect data.

\section{Results}

The findings showed that Jinja Referral Hospital uses manual records management system in the creation, maintenance, and usage of records. Findings, there were challenges related to misfiling and missing patient folders which sometimes lead to the creation of new patient folders. Also, the study discovered that the time spent in the retrieval of patient folders could negatively affect the timely delivery of healthcare services.

\section{Conclusion}

The creation, maintenance, use, and disposal of medical records at the jinja referral hospital are currently effective under control. This is supported by the fact that there is a consistent system of creating records, classification, and retrieval.

\section{Recommendations ${ }^{a}$}

The study recommended the adoption of electronic records management system as most public healthcare institutions in the country are rapidly shifting to electronic management systems. The use of electronic records management system is believed to be efficiently and effectively promote easy accessibility, retrieval of patient medical records, and allow easy communication amongst the healthcare service institutions and healthcare practitioners.

\footnotetext{
a Submitted: $17^{\text {th }} / 10 / 2021$ Accepted:

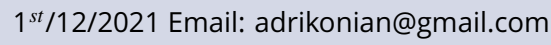

\section{Background}

Hospitals, both public and private, create, receive and maintain records as evidence of their functions, activities, and transaction. Any information documented as a result of processes and activities of a particular business is a vital asset of an organization as any other vital assets including finance and human resources (Delosa and Jr, 2020). 
Moreover, records in an organization are a unique and irreplaceable source of information about its work, achievements, and continuity. The record serves as a reliable and authentic source of information that must retain its originality throughout its use. Dikopoulou et al., (2010) pointed out that organization keeps their records to promote accountability and also are important in the planning and decision-making processes. Kemomi and Ngulube (2007) opine that an effective records management program is a key component of any public sector for efficient and enhanced service delivery.

Service delivery is important to both public and private organizations. (Arries, Ebin and Newman, 2008) assert that service delivery has become an increasingly important concern of public healthcare services. The authors maintain that healthcare service delivery can be measured by reliability, responsiveness, courtesy, customer orientation, and confidentiality and caring. To promote efficient healthcare service delivery, healthcare facilities need to create people-driven services that are characterized by quality, equity, timorousness, and a strong code of ethics (Arries, Ebin and Newman, 2008). Record management is vital to service delivery by any institution or organization. (Kemoni and Ngulube, 2007) pointed out that misfiled and lost records are likely to delay the service and hence dent the image of any service provider.

\section{Medical records.}

A medical record is an important document that is used by healthcare institutions and practitioners to record patient history, illness, and treatment (Mogli, 2009). A medical record is created as evidence of an interaction between a patient and health care personnel during a patient's visit to a healthcare facility. The interaction may involve, among other things, the recording of information about biographic data as well as temperature, blood pressure, and diagnostic test results. It also may document operations and forms of treatment. (Steward, 2005) points out that medical records form an integral part of healthcare service delivery as they contain critical information whose primary purpose is to facilitate the continuum of care and treatment of patients.

\section{Management of medical records.}

The management of medical records has a long history .for a long time medical records have been in paper format. However, expansion in the healthcare service has seen paper format becoming more problematic. In the united states of America (USA), for example, the amount of patient information on paper and the lack of a central storage system led to large volumes of medical records being stored in various locations it will be also noticed that the storage often had fragmented, inaccurate, incomplete, duplicative, and poorly documented information (Steward, 2005). The paperbased records had problems communicating essential information necessary for quality and efficient patient care. the filing created problems in retrieving medical records. The paper lacked uniformity across departments and patient information will be captured differently. In Hong Kong the paper-based medical records posed some challenges of retrieval and sharing of patient medical information due to lost and misplaced records (Ting et al., 2011). To overcome problems associated with paper-based records many countries, especially in the developed world, adopted the use of information technology for better effective use of medical information to improve health care services delivery (Al-azni et al., 2009).

Admittedly, in developing countries, the management of medical records has not been taken as a priority and is generally inadequately supported and poorly managed. In Ethiopia, for example, medical were commonly missing, incomplete and inaccessible while in Ghana the management of medical records faced many obstacles including ineffective filing and retrieving due to poor or unsuitable storage facilities (Williams\& Boren 2008).

\section{Health care service delivery}

Healthcare service is not a new phenomenon but can be traced back to ancient civilizations. the healthcare services delivery will be a contact between a healthcare provider and the healthcare consumer. According to the author, the physicians or health service providers obtained vital data from the patient and retained it for future references. Before the invention of paper and eventually communication technologies such data were stored on various media including clay or wax tablets and animal skins inarguably healthcare services revolved around a patient's record as it still does at present.

In Uganda, healthcare services are categorized into three levels; the primary care level, district Hospitals, and tertiary level hospitals. Jinja Referral hospital falls under the second level, district hospitals. The common entry point to healthcare service is at the primary care level which comprises clin- 
ics and other healthcare services. Consumers of healthcare services at the primary healthcare level may be referred to the next level of healthcare services. Local clinics of the surrounding communities under Jinja County refer their patients to Jinja Referral Hospital. (Arries and Newman, 2008) aver that healthcare service delivery to the public has been made a constitutional right. The importance and quality of the healthcare service delivery are guided by the principles of Batho Pele (Uganda, 2007).

Unarguably, the provision of quality healthcare service cannot be delinked from, among other things, sound records management programs. (Kemoni and Ngulube, 2008) opine that there is a direct link between effective records management and enhanced service delivery, hence good record keeping is the key to enhanced public healthcare service delivery. This then suggests that for the organization to render quality and efficient service to its users' needs to have a good record-keeping system. Hospitals just like any other organization have to adopt an effective records management system for quality health care service delivery as the medical records have a direct link to the delivery of healthcare services. According to Aries and (Newman, 2008), health consumers are placed at the center of healthcare service delivery. In tandem with the principles of Bath Pele, healthcare service delivery should be driven by the vision of transparency, efficiency, effectiveness, accountability, and responsiveness to the needs of patients. In public hospitals, the state is the primary provider of the HealthCare services delivery, and therefore quality healthcare services are expected by the consumers. According to this author, some hospitals use electronic record systems while others use both manual and electronic records systems. Good and accurate keeping, as well as the communication of clinical information between health practitioners, is essential for good and quality healthcare practice.

In Uganda, there are types of widely used records, the facility held Record (FHR) and the patient held record (PHR). The FHR is kept in the facility and remains the product of that facility while the PHR is kept by the patient and can be used at any healthcare facility to provide the continuum of healthcare. The FHR is widely used by the hospitals while the PHR whenever they visit other health care facilities as this record contains history patient health information.

\section{Methodology.}

\section{Study area.}

Historically, Jinja Regional Referral hospital was started during the $1^{\text {st }}$ world war of 1914-1618 with three structures built in 1920 and few British doctors. The health workers had one cardinal duty of treating the wounded kings, African riffles and army men.

After independence in1962, Uganda doctors, nurses and allied health professionals fully took over the expanded management of the hospital. This increasingly expanded the capacity of the hospital and in 1998; it was made one of the eleven referral hospitals in Uganda it is a 500 bed capacity hospital that serves the original Busoga region. This includes the districts of Jinja,Iganga, Kamuli, Bugiri,Kaliro, Mayuge and Namutumba with a population of fur million people the hospital serves the districts of Kayunga and Mukono an additional population of two million people.

The hospital supervises seven referral hospitals in the region and over 15 health centers IV. The hospital has a work force of 365 health workers and has the department of internal medicine, Nutrition, General Surgery, Obstetrics and Gynecology, Finance and Administration and Health community which are headed by senior Consultants.

The hospital is comprised of the following units too, laboratory, radiology, dental, ophthalmic, E.N.T (Ear, Nose and Throat), pediatrics, orthopedic, anesthesia and human resources. The hospital receives patients through referral from health centers Ivor the referral hospitals while others come directly to receive health care.

\section{Research methodology}

This study employed both qualitative and quantitative approaches. The rationale for using both qualitative and quantitative approaches was to collect data to explain the aim of the research. The use of both approaches helped to gain advantages of both qualitative and quantitative approaches and make up for the disadvantages and weakness of each. According to Creswell (2003) the use of both approaches tends to improve the quality of research as the weaknesses of one approach is covered by the strength of the other method. A combination of more than one research approach or triangulation in this research gave the researcher the opportunity to collect numeric data and the feeling, opinions, and interpretations of both the providers 
and users of the healthcare services based on the management of medical records at Jinja Referral Hospital.

\section{Research design.}

The study employed a cross-sectional study design.

Validity and reliability of the study

The researcher will use triangulation to examine evidence from the data source to build coherent justification for themes.

\section{Data analysis}

The data collected from the field were categorized and coded in preparation for analysis using the statistical package for the social sciences (SPSS).

\section{Ethical considerations}

The nature of the study to be conducted was explained to the participant and extend the choice of participating or not to participate. In conducting the study, the researcher ensured that the respondents were free of harm and the information gathered was strictly used for the purposes. The respondents were also be assured that their participation in the study as being strictly voluntary and be requested to sign an informed consent form. The respondents were also assured of anonymity and confidentiality.

\section{Results and discussion: Demographics of the study participants Gender of service providers \\ Gender distribution of service users}

The study had $16(53 \%)$ female and $14(47 \%)$ male participants. More females than males used the service during the time the study took place.

\section{Age distribution of the study participants}

The age ranges were used to categories the sample of the study participants. Table 3 reveals that most (83\%) of the respondents are between the ages of 21 and 40 which is the youthful age in the life of humankind. The lower percentage (17\%) of respondents is above age 40 .the age range started at 21-40 years because the study targeted the users who can use healthcare services without the assistance of parents or guardians.

\section{Working experience of respondents}

reveals that most (83\%) of the respondents have worked from 5 to 10 years giving them high working experience in the facility. the lower percentage (17\%) of respondents worked for above 10 years .

\section{Education level of respondents}

As indicated in table 5, out of the total who responded to the questionnaire, $53 \%$ had certificate, $27 \%$ had diploma, $13 \%$ had bachelor's degree education and $7 \%$ of the respondents had master's degree.

\section{Training received by respondents}

The researcher sought to know the competences of the service providers to perform their duties. Respondents were asked to indicate if they had been trained for the tasks and duties they are required to perform: $20(67 \%)$ respondents indicated to have gone for training while $12(33 \%)$ had no training as showed in the above table. Implying that the majority of the respondents went for training in the management of records and other field in the hospital.

\section{Medical records management practices \\ Record creation}

Hospitals create records on a daily basis to support their activities and transactions. The researcher sought to find out about the creation of medical at the hospital. As shown in table 8 , majority of the respondents that is $25(83 \%)$ said that the medical records at this hospital are manually created using a clean folder to register service users and 5(17\%) were not sure whether the records are crated or not. The patient is not required to pay a registration fee, show his/her identity document (ID) and a referral letter from a local clinic the medical record contains patient's personal and medical information. The process is completed by giving a patient a card which should be produced during the next hospital visit. After creating a record, patient waits to be examined.

\section{Rate of medical records creation}

The researcher sought to establish the rate at which records are created on a daily basis .4(4\%) respondents indicated that medical records that are created on a daily basis are more than five $, 8(9 \%), 14(15)$ respondents indicated that medical records that are created on a daily basis are more than ten,18(19) respondents indicated that medical records that are created on a daily basis are more than fifteen and the majority of the respondents $50(53 \%)$ said that the daily record creation is between 25 and above medical records. to verify the rate of record creation the researcher asked the hospital records administrator to shed some light on the matter. The hospital administrator in- 
Table 1. Shows the gender of service providers.

\begin{tabular}{lll}
\hline Responses & Frequency & Percentage \\
Male & 20 & 67 \\
Female & 12 & 33 \\
Total & 60 & 100 \\
\hline
\end{tabular}

Source: primary data, 2019

Table 2. shows the gender distribution of service providers

\begin{tabular}{lll}
\hline Responses & Frequency & Percentage \\
Male & 14 & 53 \\
Female & 16 & 47 \\
Total & 30 & 100 \\
\hline
\end{tabular}

Source: primary data, 2019

Table 3. Shows the age of respondents.

\begin{tabular}{lll}
\hline Responses & Frequency & Percentages \\
21-30yrs & 15 & 50 \\
31-40yrs & 10 & 33 \\
$41-50 y r s$ & 3 & 10 \\
$51-60 y r s$ & 2 & 7 \\
Total & 30 & 100 \\
\hline
\end{tabular}

Source: primary data, 2019

Table 4. Shows the distribution of respondents by working experience.

\begin{tabular}{lll}
\hline Responses & Frequency & Percentage \\
$0-5$ yrs. & 15 & 50 \\
$6-10$ yrs. & 10 & 33 \\
$11-15 y r s$ & 3 & 10 \\
$16-20 y r s$ & 2 & 7 \\
Total & 30 & 100 \\
\hline
\end{tabular}

Source: primary data, 2019

Table 5. Shows the distribution of respondents by academic qualification

\begin{tabular}{lll}
\hline Responses & Frequency & Percentage \\
Masters & 2 & 7 \\
Degree & 4 & 13 \\
Diploma & 8 & 27 \\
Certificate & 16 & 53 \\
Total & 30 & 100 \\
\hline
\end{tabular}

Source: primary data, 2019 
Table 6. shows the level of training of respondents.

\begin{tabular}{lll}
\hline Responses & Frequency & Percentage \\
Yes & 20 & 67 \\
No & 12 & 33 \\
Total & 60 & 100 \\
\hline
\end{tabular}

Source: primary data, 2019

Table 7. shows the medical record creation.

\begin{tabular}{lll}
\hline Responses & Frequency & Percentage \\
Yes & 25 & 83 \\
No & 5 & 17 \\
Total & 30 & 100 \\
\hline
\end{tabular}

Source: primary data, 2019

Table 8. Shows the daily creation of medical records.

\begin{tabular}{lll}
\hline Responses & Frequency & Percentage \\
$0-5$ & 4 & 4 \\
$5-10$ & 8 & 9 \\
$10-15$ & 14 & 15 \\
$15-20$ & 18 & 19 \\
$25+$ & 50 & 53 \\
Total & 94 & 100 \\
\hline
\end{tabular}

Source: primary data, 2019

dicated that the hospital that the hospital creates more than 25 medical records each day.

He also stated that on Mondays the hospital receives more patients than other days of the week and therefore the number of records created tends to be more than 25 since it is beginning of the week.

\section{Retrieval of medical records}

The researcher sought to determine the system and tools used for retrieving medical records when patients visit the hospital. The respondents were asked to indicate the procedure used to retrieve medical records. $25(73 \%)$ respondents indicated that medical records are retrieved manually .5(27\%) respondents were not sure of the system used for retrieving records in the system.

What do you use in the maintenance of medical records?

The researcher sought to determine the system and tools used for maintaining medical records in the hospital. 16(53\%) respondents indicated that medical records are maintained using the computers, $8(27 \%)$ respondents indicated that records are maintained by filling, $4(13 \%)$ indicated records are maintained by using cabinet and $2(7 \%)$ indicated records are maintained using shelves which implies that there is improved maintenance of records in the hospital quick service delivery and limited loss of records.

\section{Does the hospital have a records manage- ment system in place?}

Majority of the respondents 25(83\%) agreed with the statement and the rest the hospital has a records management system and 5(17\%) respondents were not sure whether has the records management system or not.

\section{Which type of records management system does the hospital use?}

As shown in table 12,15(50\%) responded that the hospital uses a centralized system of records management ,10(33\%) responded that the hospital also uses decentralized system of records management especially in administration and $5(17 \%)$ of the respondents were not sure of whether the hospi- 
Table 9. Shows the medical records retrieval

\begin{tabular}{lll}
\hline Responses & Frequency & Percentage \\
Manual & 25 & 87 \\
Not sure & 5 & 17 \\
Total & 30 & 100 \\
\hline
\end{tabular}

Source: primary data, 2019

Table 10. Shows the maintenance medical records retrieval

\begin{tabular}{lll}
\hline Responses & Frequency & Percentage \\
Filling & 8 & 27 \\
Cabinets & 4 & 13 \\
Shelves & 2 & 7 \\
Computers & 16 & 53 \\
Total & 30 & 100 \\
\hline
\end{tabular}

Source: primary data, 2019

Table 11. Shows the availability of records management system

\begin{tabular}{lll}
\hline Responses & Frequency & percentage \\
Yes & 25 & 83 \\
No & 5 & 17 \\
Total & 30 & 100 \\
\hline
\end{tabular}

Source: primary data, 2019

Table 12. Shows the type of records management system the hospital has.

\begin{tabular}{lll}
\hline Responses & Frequency & Percentage \\
Centralized & 15 & 50 \\
Decentralized & 10 & 33 \\
Not sure & 5 & 17 \\
Total & 30 & 100 \\
\hline
\end{tabular}

Source: primary data, 2019

tal has any records management system used for record keeping in the hospital or not .

\section{How long does it take to retrieve a patient} file?

The speed of service is one of the key components of any service delivery. Excessive waiting periods in hospitals are often caused by the wasteful processes before or after treatment .this is often caused by the spent in locating the medical records of patients. The respondents were asked to determine the length of time spent in retrieving an individual patient folder. Out of 30 respondents ,25(83\%) indicated that it takes approximately 5 minutes to retrieve a folder,3(10\%) summarized that it takes 10 minutes, $2(7 \%)$ said that it takes ten minutes and no responses was registered on above fifteen minutes.

The researcher observed that the retrieval of folders is generally quick except for those users who revisit the hospital after a long time. It is probable that their records may have been placed outside the office holding current records.

Who is responsible for the overall management of medical records in this hospital?

As shown in table 14, 20(67\%) responded that the health records clerks are the once in charge

the overall management of medical records in the hospital, $5(16 \%)$ of the respondents in- 
Table 13. Shows the length of retrieval time records in the hospital

\begin{tabular}{lll}
\hline Responses & Frequency & Percentage \\
5 minutes & 25 & 83 \\
10minutes & 3 & 10 \\
15minutes & 2 & 7 \\
+15 minutes & 0 & 0 \\
Total & 30 & 100 \\
\hline
\end{tabular}

Source: primary data, 2019

Table 14. shows the personnel responsible for the overall management of records.

\begin{tabular}{lll}
\hline Responses & Frequency & Percentage \\
Doctor & 2 & 7 \\
Health records clerks & 20 & 67 \\
Hospital records administrator & 5 & 16 \\
Nurses and midwives & 3 & 10 \\
Patients (healthcare users ) & 0 & 00 \\
Total & 30 & 100 \\
\hline
\end{tabular}

Source: primary data, 2019

dicated that medical records are managed by hospital records administrator,3(10\%) indicated that records are managed by nurses and midwives,2(7\%) records are managed by doctors and response was recorded on whether the records are managed by patients( health care users ) or not implying that records are managed by health record clerks in the hospital quick service delivery.

\section{How frequent are the medical records col- lected from other units?}

\section{Waiting periods for service.}

The time factor is important in healthcare delivery. He maintains that healthcare organizations must strive to balance customer demands as excessive delays may delay diagnosis and therefore put the patient's health at risk. When the service use study participants were asked if they got their folders on time when reporting to the registration point, $25(83 \%)$ indicated that their folders were retrieved quickly while $5(17 \%)$ indicated to have waited longer for their folders to be retrieved.

An interview with the hospital records administrator revealed that the retrieval of folders should take approximately 5 minutes except on very busy days.

\section{Are the in-patient kept separate from the out-patient records?}

Filing of in-patient and out-patient folders.
The hospital wards may produce large quantities of records and may decide to maintain their records either centrally or in the wards. Hospitals generally have two types of patients; in-patients and out-patients. The researcher sought to find out whether the two categories of patients' records were filed and kept separately. 25(83\%) respondents asserted that the storage of in-patient and out-patient records is not separate. $5(17 \%)$ respondents stated that the storage of these folders is separate. This was verified by the hospital records administrator who indicated that the hospital is using a centralized records registry system. The in-patients remain in the wards until the patients are discharged, after which they are collected to be filled and kept in one central place. The researcher noted that all folders are kept in one centralized storage place. When the patient is admitted to the hospital wards then the folder will be kept in the ward after the patient is discharged the folder will be taken back to the central storage place.

Infrastructure for the management of medical records

Do you consider the patient registration space and the waiting are as adequate?

The study also sought to establish the type of material and tools used for patient identification.

The respondents were asked to state if there was proof of registration given to patients to have 
Table 15. Shows the registration of patients.

\begin{tabular}{lll}
\hline Responses & Frequency & Percentage \\
Yes & 25 & 83 \\
No & 5 & 17 \\
Total & 30 & 100 \\
\hline
\end{tabular}

Source: primary data, 2019

a unique identity. The results were that 25(83\%) respondents stated that a confirmation of registration in the form of a hospital identity card is issued to the patient. Only 5(7\%) respondent were not sure of the statement.

As the issue of patient identification is a crucial element in the healthcare service, it was imperative for the researcher to observe the phenomenon. The researcher observed that after registration, each patient is given a card with a number similar to the number on top of the folder.

The card is used each time the patient visit the hospital.as some patients are referred to the hospital by their local clinics. They are expected to bring along their small books from their clinics. The folder number written on the card will also be written on that small book or patient held record used in the clinic each card number is unique to each patient, which fast tracks retrieval of the folder.

Which of the following equipment does the hospital used to keep the patient folders?

In an ideal hospital, a well-organized filing system is essential for the effective storage and retrieval of patient records. An effective filing system is required for the facilitation of continuity of patient care among healthcare providers. A "paper-based medical records requires filing equipment for storage of records and enable easy location of folders" it was, therefore, essential to find out the type of filing equipment used at the Jinja referral hospital for the storage of medical records. Consequently, $16(64 \%)$ respondents answered that the hospital uses shelves, $8(27 \%)$ answered that the hospital uses filing cabinets and $6(20 \%)$ indicated the hospital uses computers for keeping records. The researcher verified that from the hospital records administrator who then confirmed that the hospital uses shelves, computers, and filing cabinets to store medical records in a file room .same as the observation in which the researcher noted that the hospital uses shelves, computers, and filing cabinets which are situated behind the clerk's desk.

\section{Where are the medical records kept in this hospital?}

Healthcare facilitates storing and retaining medical records for easy retrieval. The researcher explored the storage facilities for medical records at the jinja referral hospital. The respondents were asked to state where the medical records were kept in the hospital.it turned those $25(83 \%)$ respondents stated that medical records were kept in the registry $; 3(10 \%)$ respondents stated records are kept in administration and $2(7 \%)$ of the respondents stated that records are kept using computers in the hospitals.

\section{Are all medical records kept in one place?}

Healthcare facilities store and retain medical records for easy retrieval. the researcher explored the storage facilities for medical records at the jinja referral hospital. the respondents were asked to state where the medical records were kept in the hospital.it turned out that $28(93 \%)$ respondents stated that medical records were kept in one place while $2(7 \%)$ respondents were not sure of the storage place.

\section{In which format are they?}

Most hospitals, especially in developing countries, generate large quantities of paper-based data which results in the increase of volumes and potential difficulties in retrieving information.

Globally, the healthcare sector has embraced the benefits of maintaining electronic medical records for faster retrieval and flow of information. The respondents were asked to indicate the recording medium used by their hospital.25 (83\%) stated that the hospital uses paper-based medical records, 3(10\%) uses electronic-based medical records and 2(7\%) asserted that both paper-based and computer-based records are created at the hospital. The hospital records administrator said that jinja referral hospital, like other hospitals, uses paper-based medical records. Through observation, the researcher observed that new folders are created manually using paper-based folders, and 
Table 16. Shows the equipment used for patient folders.

\begin{tabular}{lll}
\hline Responses & Frequency & Percentage \\
Filing cabinets & 8 & 27 \\
Shelves & 16 & 53 \\
Computers & 6 & 20 \\
Total & 30 & 100 \\
\hline
\end{tabular}

Source: primary data, 2019

Table 17. Shows the storage place of medical records.

\begin{tabular}{lll}
\hline Responses & Frequency & Percentage \\
Registry & 25 & 83 \\
Administration Clerk's Offices. & 3 & 10 \\
Computers & 2 & 7 \\
Total & 30 & 100 \\
\hline
\end{tabular}

Source: primary data, 2019

Table 18. Shows the medium of medical records

\begin{tabular}{lll}
\hline Respondents & Frequency & Percentage \\
Paper & 25 & 83 \\
Electronic & 3 & 10 \\
Both formats & 2 & 7 \\
Total & 30 & 100 \\
\hline
\end{tabular}

Source: primary data, 2019

the clerk records each coming patient in the registration logbook available at the registration desk. The records were also retrieved manually by using the folder number which is available on the hospital visiting card. The clerks search for the folder manually in the shelves which are filed in numerical order until it is retrieved.

\section{Legal and regulatory framework.}

Does the hospital follow any existing legislation and guidelines that regulate the creation of medical records?

\section{Policy awareness}

As much as the government departments are required to establish policies that regulate records management activities, the policies should be communicated and implemented. The researcher wanted to establish if the respondents were aware of the policy that regulates the management of records in the hospital. The response showed that respondents were conversant with the policy. $25(83 \%)$ respondents were aware of the policy. 3 (10\%) did not respond and $2(7 \%)$ of the respon- dents were not sure whether the hospitals' hard policies or not. Policies should be approved and widely publicized to create awareness about their availability. The proper use of these policies prevents possible shortcomings in the management of medical records. The hospital records administrator

Pointed out that those managing and using medical records are quite aware and conversant with the policy regulating the management of medical records.

Ngope and Van Der Walt (2009) insist that the policy should be communicated to the officials to manage records accordingly. The hospital records administrator confirmed that the policies are communicated to healthcare workers and professionals. There is in-service training to ensure that staff is acquainted with the stipulated policies governing records management.

Nengomasha (2009) observes that training all officials on record-keeping would prevent unaware- 
ness, but without proper training, the set policies are of no importance.

Do you have rules governing access to medical records in this hospital?

\section{Availability of records management policy.}

The medical protection society (South Africa, 2012) states that the management of medical records facilitates continuity of care for patients and reduces risks of adverse incidents that might be caused by lost, untraceable, or misplaced medical records. Chachage and Nhulube(2006) underscore the fact that many countries pass legislation that requires businesses and organizations to manage their records to ensure easy access when needed. The results showed that the hospital does abide by national standards on medical records management. the majority (83\%) of respondents stated that there is a policy for the management of medical records and this was also confirmed by the hospital records administrator .3(10\%) did not respond and $2(7 \%)$ of the respondents were not sure about the availability of such a policy .as regards the mode of implementation of this policy, the hospital records administrator indicated that the policy is implemented by the hospital management and supervisors.

Is access to medical records open to everyone?

\section{Rules for accessing records}

The Uganda Public Health Act (1935) asserts that everyone who is in charge of a user's healthcare record must set up control measures to restrict unauthorized access to health records and storage facilities. the act makes it an offense for anyone to access or copy patient information without authorization. The study sought to establish if the hospital does have rules that govern access to medical records. The respondents were asked to indicate if there were rules that govern access to medical records; $3(10 \%)$ respondents maintained that there were no rules for preventing access while $2(7 \%)$ respondents were not sure about such regulations. hospital records administrator was interviewed on this matter, it was established that regulations were restricting unauthorized access to medical records.

Does the hospital have a records management policy for managing medical records?

The management of records in the public sector in Uganda is impacted by various legislations including the Bill of Rights as enshrined in the constitution of Uganda. The national records and archives act 2001 and the promotion of freedom of access to information (2005). The management of medical records is subject to the stipulations of the Uganda public health act (1935). The act requires that any person who is in charge of a health establishment must create and maintain a health record for every user of the health service. Respondents were asked if they were aware of the national legislation that governs the management of patient health information: $25(83 \%)$ respondents indicated that the hospital is aware of the national legislation that regulates the management of health information, $3(10 \%)$ respondents indicated that the hospital staff was not aware of the policy and 2(7\%) respondents were not sure if they were aware of all the national legislation about the management of medical records.

\section{How are medical records disposed of? Disposal of medical records}

By the guidelines of the Uganda Public Health Act (1935), a health record should be stored in a safe place for not less than 6 years from the time the record becomes dormant. The national records and archives act 2001 states that no public record under the control of the government's body may be transferred to the archives' repository, nor destroyed, erased, or disposed of without a written disposal authority. this study further sought to establish if the hospital had disposal schedules for non-current medical records. 20(67\%) respondents maintained that the hospital preserves medical records for a specified time,2(7\%) respondents said the hospital does not preserve records while $8(26 \%)$ respondents were not sure whether the hospital preserved medical records or not.

The hospital records administrator indicated that the medical records are preserved for a specific period in line with the requirement of the Uganda public health act (1935).

Are all hospital staff conversant with such a policy?

Compliance with medical records management policy

The research sought to examine if the management of medical records in the hospital complied with existing requirements for the management of medical records. All respondents indicated that the hospital uses only one records management program for all types of hospital records.

This was confirmed during an interview with the hospital's records administrator. The hospital 
records administrator explained that, although the medical records were not managed separately, specific procedures were governing their filing, storage, and retrieval

Does the hospital aware of the national legislations that regulate the management of patient health information.

\section{Records management program.}

Dikopoulou et al. (2010) stipulate that to achieve efficient use of recorded information, there must be control production, transfer, retention, use, and disposal .all respondents agreed that jinja's referral hospital has a records management program in place.

The hospital records administrator confirmed that the hospital does have a records management program responsible for the management of hospital records.

Security of medical records show, are medical records secured?

The world health organization (2006) considers information in a medical record as privileged communication between a patient and a healthcare professional hence it requires guaranteed security. The respondents were asked to specify how medical records were secured in the hospital.25 (83\%) of the respondents indicated that medical records were kept in strong rooms, $3(10 \%)$ responded that records were kept in Burglar proofed rooms while $2(7 \%)$ said they were kept in the special rooms.

How is the movement of patient folders within the hospital units regulated?

\section{Movement of patient folders}

The study also investigated if there were any measures to control the movement of patient folders within the hospital. The discussions with respondents revealed that patient folders are left at the dispensary after consultation in some cases, users get their treatment at the dispensary and leave their folders there .all folders left at a dispensary are sent to the medical records department for filing .when the folder is not found from where it is supposed to be, it is tracked through the daily register which is normally kept by the clerks. The respondents also pointed out that should the folder be borrowed by another unit, that unit should sign and return that folder to the file area. If not yet returned, the nurses should search for it and return it to the medical records department for filing.

Is there any system to keep borrowed patient folders by other hospital units?
Shepherd and Yeo (2003) contend that records must be protected against long-term loss and misplacement, and safeguarded against malicious acts or carelessness on the part of the staff that has legitimate access to them. The paper-based folders are protected from temporary misplacement or long-term loss through the use of signatures, whoever has borrowed a folder must sign in the borrower's register to ensure the return of the borrowed folders. The researcher asked about the system the hospital employs to track the medical records issued out to other

Hospitals units .25(83\%) respondents indicated that there were tracked and traced through a register housed at the medical records department. when the folder is issued out, it is indicated in the register. If it is issued to a patient, the patient goes to the examination room, and after collecting medication at the dispensary. The record is left there to be collected by hospital staff for filing at the medical records department.5 (17\%) respondents explained that there was no system for tracking and tracing records.

How is the patient health information protected from unauthorized alteration?

\section{The authenticity of medical records}

The national records and archives act (2001) stipulate that an original medical record must always remain intact and fully legible. The medical protection society (Uganda, 1892) rules that an entry made to a medical record neither be deleted nor obliterated. The study further probed the authenticity of medical records at the jinja referral hospital. All 30(100\%) of the respondents stated that unauthorized officials were not given any information contained in medical records thus the door leading to the folders was always blocked to prevent such access in the event of an investigation, clerks or nurses safeguard medical records by making photocopies of the originals before the investigation. The interviews with the key informant, the hospital records administrator, revealed that medical records cannot be tampered with because medical records are protected by color-coded paper.

\section{Conclusion and} recommendation. Summary of the findings. 
Table 19. Shows the security of medical records

\begin{tabular}{lll}
\hline Responses & Frequency & Percentage \\
Strong rooms & 25 & 83 \\
Burglar proofed rooms & 3 & 10 \\
Special rooms & 2 & 7 \\
Total & 30 & 100 \\
\hline
\end{tabular}

Source: primary data, 2019

Table 20. Shows tracking and tracing of medical records.

\begin{tabular}{lll}
\hline Responses & Frequency & Percentage \\
yes & 25 & 83 \\
No & 5 & 17 \\
Total & 30 & 100 \\
\hline
\end{tabular}

Source: primary data, 2019

This sub-section provides the summary of the findings of the study are based on the research objectives which sought to:

1) Describe the present records management practices in a jinja referral hospital.

2) Find out the existing infrastructure for the management in jinja referral hospital with the relevant legal and regulatory framework.

3) Find out the security of medical records in a jinja referral hospital.

4) Creation and management of medical records

5) The study established that jinja referral hospital uses a paper-based manual medical records management system which is centralized. At the time of the study, this system was serving the hospital without any problems. The few notable problems included the loss or misplacement of patient files which necessitated the opening of temporary files. The use of temporary files carried the risk of compromising the quality of healthcare services given since the health professionals were unable to benefit from the previous healthcare history with a temporary file.

6) The accrual of medical records creation at the hospital was found to be moderate with Mondays identified to be the most notable peak periods creation.

7) Infrastructure for the management of medical records.

8) The study that the hospital has adequate space for the registration area which is also used for interacting with patients on any other issue besides registration. Personnel dealing with registration have sufficient working space and are situated in an area that is easily noticeable and approachable by outpatients.

9) The records are centrally filed and kept in wellmaintained filling equipment and storage place.

10) The entire records management program of the hospital is under the supervision of the hospital records administrator. the staff working on the records unit have been exposed to basic training on records keeping and seem to be conversant and regulations governing the management of records in general and medical records in particular. No mention was of unique training on medical records management or use of information technology in medical records keeping.

\section{Legal and regulatory requirements.}

1) The study established that the hospital complied with the relevant legal and regulatory requirements for the management of medical records.

2) The policies and regulations are appropriately communicated to staff from time to raise their awareness as well as the importance of complying with and implementing such policies and regulations.

\section{Security of medical records}

The results of the study indicated that the hospital keeps all medical records in secured and safe and lockable storage rooms. The security is aimed at safeguarding the originality and authenticity of the records against any possible alteration or theft. 
The study findings also established that the hospital controls the movement of medical records by making sure that borrowed medical record is indicated in a register .this is used as an attacking system to ensure that medical records are not easily misplaced and are properly accounted for.

This sub-section provides the summary of the findings of the study are based on the research objectives which sought to:

Describe the present records management practices in a jinja referral hospital.

Find out the existing infrastructure for the management in jinja referral hospital with the relevant legal and regulatory framework.

Find out the security of medical records in a jinja referral hospital.

\section{Creation and management of medical records}

The study established that jinja referral hospital uses a paper-based manual medical records management system which is centralized. At the time of the study, this system was serving the hospital without any problems. The few notable problems included the loss or misplacement of patient files which necessitated the opening of temporary files. The use of temporary files carried the risk of compromising the quality of healthcare services given since the health professionals were unable to benefit from the previous healthcare history with a temporary file.

The accrual of medical records creation at the hospital was found to be moderate with Mondays identified to be the most notable peak periods creation.

\section{Infrastructure for the management of medi- cal records.}

The study that the hospital has adequate space for the registration area which is also used for interacting with patients on any other issue besides registration. Personnel dealing with registration have sufficient working space and are situated in an area that is easily noticeable and approachable by outpatients.

The records are centrally filed and kept in wellmaintained filling equipment and storage place.

The entire records management program of the hospital is under the supervision of the hospital records administrator. The staff working on the records unit have been exposed to basic training on records keeping and seem to be conversant and regulations governing the management of records in general and medical records in particular. No mention was of unique training on medical records management or use of information technology in medical records keeping.

\section{Legal and regulatory requirements.}

The study established that the hospital complied with the relevant legal and regulatory requirements for the management of medical records.

The policies and regulations are appropriately communicated to staff from time to raise their awareness as well as the importance of complying with and implementing such policies and regulations.

\section{Security of medical records}

The results of the study indicated that the hospital keeps all medical records in secured and safe and lockable storage rooms. The security is aimed at safeguarding the originality and authenticity of the records against any possible alteration or theft.

The study findings also established that the hospital controls the movement of medical records by making sure that borrowed medical record is indicated in a register .this is used as an attacking system to ensure that medical records are not easily misplaced and are properly accounted for.

\section{Conclusion}

\section{From the summary of the findings, the follow-} ing conclusion can be made.

The creation, maintenance, use, and disposal of medical records at the jinja referral hospital are currently effective under control. This is supported by the fact that there is a consistent system of creating records, classification, and retrieval. This has resulted in a few missing or lost records. Medical records are directly related to quality healthcare service delivery. A failure to retrieve a patient folder that contains a medical record of that particular patient may have implications on the medical prescription, reordering of diagnostic tests which are sometimes expensive to reproduce, and the loss of precious health information history. Jinja referral hospital falls under the first level of health service in the district hospitals. The district hospitals use manual records management system which has its flaws of access, an increase of paper files, retrieval, and lost or missing files.

There is adequate infrastructure for the management of medical records at the hospital at least at present. The recent refurbishing of the hospi- 
tal's physical infrastructure has provided adequate equipment, and working outpatient space for the management of records. The current staff complement seems adequate for the task of managing the records. Medical records are created daily increasing volumes of the image, the files stored on the shelves which in the future could be a hindrance to timeous healthcare service delivery. On a tightly packed shelf the paper files get easily damaged, the spine of the file becomes soft and brittle and that could shorten the life span of a record.

The hospital complies with all the legislative and regulatory requirements about medical records keeping. Healthcare workers in jinja referral hospitals sound quite conversant with the policies and procedures that govern the creation, use, and maintenance of medical records. The disposal of medical records needs to be worked on by the hospital as the creation of paper medical increases daily. A sound disposal policy ensures adequate records storage.

The security and storage of medical records are adequate. medical records are stored and locked in a safe place that is far from the reach of an authorized person, however, strict measures in the wards should be exercised to prevent the folders from unauthorized access, the paper medical records can only be found in one place at a time, the collection of these records from various hospitals units depending from where the patient left it can harm service delivery. The folder tracking and system could also affect and impact the healthcare service delivery as all the systems are done manually.

\section{Recommendations.}

An effective and efficient records management program is important to an organization.

According to Kemoni and Ngulube (2008) records management is an important component to the survival of any public sector .this study aimed at finding out the management of medical records at the jinja referral hospital. Following the findings and the conclusions, the following recommendations are made.

The findings of the study established that jinja referral hospital is using manual records management system. The manual record-managed system has its flaws which jinja referral hospital is not immune to them. The problem of patient folder retrieval, missing or lost files were reported in other countries in chapter two. Medical records serve as a communication medium amongst the treat- ing physicians and therefore the missing medical records break that communication and make it difficult to decide on the diagnosis and treatment of a patient. Time spent in the retrieval of patient folders affects the quality of service it is against the problems mentioned above that the developed countries invested in the use and integration of health information technology in hospitals. In the future, the study recommends the implementation and the use of electronic medical records in jinja referral hospital .electronic medical records promotes the delivery of quality service, enhanced service, and timeous healthcare service. Efficient and effective healthcare services delivery is the envisaged service for the citizens.

\section{Infrastructure}

In terms of infrastructure, jinja's referral hospital has been recently refurbished. The study found that the space where the records clerk desk is situated is adequate registration area or reception area where patients first report when coming to the hospital and the records storage place is satisfactory. The infrastructure that is currently in use by the jinja referral hospital is adequate but needs to be reconsidered shortly. the hospital uses shelves and filing cabinets in the storage of medical records and consumes a lot of space that could have been used in other hospital business operations. The study recommends that the movable shelves be used instead of the files that are currently in use. The movable shelves consume less space and are manually controlled and power controlled. Also, the study recommends the use of an electronic medical record management system as all the records management systems, the patient health information history will always be available when needed by the physicians. One of the benefits of electronic medical records is their ability in information sharing: portability, patient health information is accessible in any of the health sectors.

\section{Security of medical records}

The hospital must keep the medical records safe and secured. Security and confidentiality is always the biggest question in keeping medical records. Presently, the hospital keeps the medical records under control but the issue of security needs to be strengthened by protecting the records against lost and missing folders. To protect the content of patient health information, the study recommends the use of cryptography, steganography and cryptography, steganography, and encryption against 
unauthorized access. in terms of confidentiality issues, the study recommends the use of a password to authenticate the right person for the health information. Above all, the use of electronic medical records is more secure and confidential than its counterpart.

\section{Area of further research}

This study focused on the management of medical records only at the jinja referral hospital. Jinja referral hospitals do produce other records either than medical records, the study recommends that another study that will focus on other records be conducted. Since the hospital is currently using the manual records management system, the study recommends another study that will look at the feasibility of the implementation of the electronic medical records system

\section{Acknowledgement.}

My special word of appreciation goes to Mr.Okechi Mathius my beloved father and Mr.Yosia Ikomo who gave me the approval to conduct the research in the hospital .I would also like to show my appreciation to the hospital clerks and the senior staff for their participation and contribution in the collection of data for the completion of this study their contribution cannot go unnoticed.

Special thanks go to my wife Asogo Sylvia and my sister Nabwire Mercy for their support and confidence showed to me. To my friends and my colleagues, thank you for your continuous support and motivation it made me to see the path I was going to.

Lam who lam today because of my grandmother and the teachers who taught me in all levels of education I have passed through to this level, Thank you all.

\section{Definition of terms}

\section{Medical record:}

Mogli (2009) defines a medical record as an orderly written of the patient that contains the history of illness, progress notes, and radiology findings, and when complete it should have included sufficient data about the diagnosis treatment, and length of hospital stay.

\section{Hospital}

A hospital as defined by Mc Way (2008) is a healthcare facility that has a governing body, an organized medical staff, and professional staff, and inpatient facilities and provides medical, nursing, and related services for ill and injured patients 24 hours per day, seven days per week.

\section{Record management program:}

Records management program as described by Shepherd and Yeo (2003) is a strategic function that is effective in setting, monitoring policies and standards for records management by designing and implementing records management system used to unify a set of resources, responsibilities, procedures, and equipment and provide easy access to records.

\section{Service delivery:}

Arries and Newman, (2008) describe service delivery as a multiphase interactive action that coincides with the dimensions of excellence, assurance of competence, attentiveness, dissemination of information by staff, and flexible helpfulness that add valuable meaning to the users.

\section{References:}

1) Al -azmi,S.F., AL-enezi, N\&Chowdhury,L et al.(2009) .users attitudes to an electronic medical record system and its correlates: a multivariate analysis. Health information management journal 38(2) https://doi.org/10.1177/1833358309038002 05 PMid:19546486

2) Arries, Ebin J and Newman, o., (2008). Outpatients' experiences of quality service delivery at a teaching hospital in Gauteng introduction and problem statement.health SA Gesondheid, 13(1), pp.41-54 https://doi.org/10.4102/hsag.v13i1.256

3) Dikopoulou,A., Mihioyis, 2010. Records management: a key element for effectiveness, accountability and development in the Greek public Adinistrator in the Greek public Administration. International journal of public Administration, 33(5), pp.262-287. https://doi.org/10.1080/0190069090 3449673

4) Delosa, S.A. and Jr, R.A.D. (2020) 'IMPLEMENTATION OF RECORDS MANAGEMENT SYSTEM IN COTABATO REGIONAL MEDICAL CENTER HEALTH INFORMATION MANAGEMENT DEPARTMENT', 8(1), p. 12.

5) Kemomi , H.N .and Ngulube P.,(2007) National Archives and the effective management of public sector records in Kenya. Mousaion, 25(2), pp.120-140.available at: http://. $\& d b=$ lih\&AN=32160306\&=ES\&SITE=ehost-live 
6) Mogli (2009).Medical Records Role in Healthcare Delivery in 21 st Century. Blueprint, 17(4), pp.209-212

7) Ngoepe , M.\& Van Der Walt,T.,2009.an Exploration of records management Trends in the south Africa public sector. Mousaion, 27(1), pp.116-136. Available at: https:// search. ebscohost.login.adpx? Direct=true\& Auth ,url,uid\&db=lih\&AN=43466168\&es\&site=ehostlive.

8) Ngulube, p. \& Tafor, V.F., 2006. The management of public records and archives in the member countries of ESARBICA .Journal of the society of Archivist, 27(August 2012), pp.57-83 https://doi.org $/ 10.1080 / 00039810600691288$

9) Steward, M., (2005). Electronic medical records .privacy, Confidentiality, Liability .The journal of legal medicine, 26, pp.491-506. https://doi.org/10.10 80/01947640500364762 PMid:16303736

10) Ting,J.S.L et.al (2011) RF-Medisys: Aradio frequency identi Acation- based electronic medical record system for improving medical information accessibility and services at point of care .management , 66(1),pp2506-19. Availability at:http://www. ncbi.nlm.gov/pubmed/18378371 https://doi.org/1 $0.1177 / 183335831104000105$ 